\title{
AN AUTOMATED INFORMATION RETRIEVAL SYSTEM DESIGN FOR INTERACTIVE REMOTE, OR ON-CAMPUS STUDENT USE
}

by Joseph F. Morrison Jr.

University of Illinois at Chicago Circle

\section{Abstract}

School based audio information systems, which allow student access to recorded language drills, supplementary textbook materials, vocabulary improvement lessons, and even classroom lectures have been proven useful in the educational process. One of the most promising means of supplementing the classroom experience with individualized instruction is through the use of audio-tutorial materials in an automated information retrieval system cesigned for interactive student participation. Heretofore, economic ar:d technical limitations have placed an upper bound on the utility of such systems.

This research is intended to accelerate future commercial development of a methodology to efficiently and economically allow student interaction with organized educational media. A prototype switchednetwork audio retrieval system has been designed and constructed. It allows for the individualized playback of tutorial material, as well as for the recording of student responses for their instructors' evaluation. A student is able to access any of thousands of currently recorded materials in a few seconds with this small-computer based design. Particular attention has been placed upon complete student control of the media through standard home push button telephones, or at special on-campus facilities.

\section{Introduction}

This is the report of a study, the results of which will hopefully lead to improvement of educational assistance and support to instruction. The motivation for this study and design stems from two fundamental considerations: first, instructional technology and media are a necessary part of our educational system today, and secondly, the quality of present audio information systems can be significantly improved by taking advantage of extremely cost effective mini-computer technology. 
The concept of individualized instruction and the desire for a student to learn at his own rate and when he is ready, have brought about the development of numerous learning aids, teaching machines, etc. Some measure of success has been experienced from these efforts, but not in proportion to the investment. In particular, audio information retrieval systems (language laboratories included) have not measured up to the expectation $(1,2,3,4)$. One major reason for the failure is the lack of true individualization.

The intent of this project is to develop an audio information retrival system which is truly individual in character. The expected result of this effort is a supplementary teaching system, which will aid the student in learning through better use of both his and the university's time and resources. With this goal in mind, the project is directed at the development of an efficient and cost-effective system which will allow the student access to any of literally thousands of recorded tapes from any touch-tone equipped telephone via the conventional telephone network, or from individual on-campus carrels. The student will have full control over lesson material at all times. The star-configured system will consist of a plurality of remote station (either on-or off-campus) and a control site housing both a minicomputer for control of all functions and a bank of automatic cassette tape recorder/players.

This report is written to foster awarercss of the audio system for which a model has been constructed, but the technical concepts are formulated to include a video cassette system for future implementation. The project will proceed in two phases, the development of a model for evaluation and the design of a pilot system based upon the experience gained from the model. This p?per is a discussion of the model.

The design is premised on the following fundamental considerations:

1. Part of the learning process is the acquistion of information which may be considered as any knowledge desired by a student in order to satisfy his living or learning needs. Heretofore this has been accomplished primarily by attendance in class and reading the printed page.

2. Learning media refer to all live presentations and recordings which serve as information sources for a student. The media of storage and method of transmission need to be distinguished. Information stored in print; by audio, video, or computer tapes or disks; are all defined as the media of storage. The method of transmission is the vehicle by which the learner accesses information. 


\section{Automated Retrieval}

3. Teaching and learning efficiency are related considerations. The institution must concern itself with maximum economy of resources. Therefore, what is being taught should be made accessible to the learner in an efficient manner.

4. The necessity to absorb a large volume of information; the broad, diversified spectrum of the learner's backgrounds; the need for educational evaluation and accountability have all been factors leading to the need for efficient individualized instruction.

5. The organizational and unifying abilities of educational institutions far exceed the corresponding resources available to an individual. Easy access to catalogued and relevant material is probably the best reason for the existarce of any centralized information. retrieval system.

These considerations are general in nature. Many different media and modes of transmission have been developed, i.e. closed circuit television, computer assisted instruction, language laboratories, media centers, all of which were designed with the above and other considerations in mind. This project is also based on these fundamental considerations, but is not intended to replace any other media, modes, or method of teaching. It is intended to enhance present existing methodology, while allowing a rational understanding to point toward the successful exploitation of future new avenues of distributed educational technology. The notion that all live teaching is personal and media is impersonal is fallacious. Media is essentially impersonal but if the student is mainly receiving information or repeating detailed examples, his task is essentially impersonal. However, large classes and lecture sections are a'so impersonal and no more humane than media devices. If the rote, repetitive tasks of information relaying and examples could be committed to tape, resulting eventually in more free time for the professor to spend with individuals, the overall teaching learning situation will in fact become more personal.

\section{Concept of the System}

\subsection{The present U.I.C.C. system}

Most efforts during the last ten years in the area of audio information retrieval systems have centered around dial access. Various systems ranging from manual connection of student headphones to sophisticated electronic switching networks have been employed in audio/visual information retrieval. Each type, from the simplest to the most sophisticated, has serious drawbacks, which the proposed system seeks to eliminate. These problems will now be elaborated upon. 
The primary difficulty with dial access audio systems is their non.individual nature. The dial station can select from a relatively few number of programs which is proportional to the number of tape playback machines available and pre-loaded with program material. The user has no control over the movement of the tape. Each tape playback machine is accessible by all dial stations, i.e. many callers may be listening to one tape resulting in the necessity for scheduling when calls could be made. The limitations of this type of system make true individual study impossible.

When at home, most students have no access to information stored in the library, on-site retrieval systems, computers, etc.; they must personally go to the campus. This may be inconvenient or impossible at the time the student needs the information or practice the most.

The existing facility of the Audio Information Service at U.I.C.C. (4) is beset by all of the above mentioned problems, but we cannot proceed on a broader, more comprehensive scale due to the basic technical limitations of our existing system. This system, manufactured by Chester Electronic Laboratories and installed in 1965, has a maximum of thirty, four track tapes available for the dial selecnoti. Aside from the aforementioned difficulties with non-individual control, the limited capacity of the system requires constant changing of over 1,000 lesson tapes currently scheduled each academic quarter. Of necessity, the student must call when and if the desired lesson is available. As above, the student has no control over the motion of the tape and may not hear the lesson from the beginning unless he happens to be the first caller. The passive, lockstep nature of the present home telephone system has obvious limitations and deterrents to individualized study.

Aural/oral testing is presently cumbersome and limited because a maximum of fifteen students (who must use the facility on campus) can be tested at a time, and all student responses must be transcribed to a different tape for each instructor. In foreign language instruction, testing has become increasingly important; the new system, with its feature of flexible computer control, offers potential solutions for many of these problems.

\subsection{Functional description of the new system.}

The model was designed with maximum individualization in mind. Recorded tapes are to be accessed from the on-campus carrels, each equipped with a push button touch-tone type panel, volume control, headset, and microphone; or from any touch-tone push type telephone via the telephone switched network. The user will, usine touchtone pushbuttons, input the four digit call number of the program he 


\section{Automated Retrieval}

desires. The minicomputer will receive the decoded numbers and process the request. The computer will first check all tape machines for the requested lesson; if the requested lesson is loaded and not in use, the computer will connect the user with the tape machine. If the requested program is not currently loaded, the computer will issue a command on a Teletype machine to the operator, telling him to load the desired tape on a certain playback machine chosen in an optimal manner. After the connection is established by the computer, the user has control of the tape machine. To illustrate the possible dialog between the student and the machine at this point in time, the following is a list of touch-tone numbers assigned as control functions: " 1 " play; " 3 " rewind; " 5 " forward; "6"; stop; "0" call system operator; "*" select new lesson; "\#" goodby. The computer will record the number of requests for each accessed tape, will optimize system usage, and perform all data management functions. The call system operator function is envisioned to add the aspect of personal attention to any confused users.

Each lesson tape will be assigned four digit call numbers and each user will have a directory of tapes in the collection. It should be noted that this system makes every tape in the collection available to every user in a matter of seconds. This is accomplished by having multiple copies on hand. However, it does not employ expensive high speed on line duplication of tapes nor limit in any way the number of lessons a student terminal can access.

The Physical layout of the equipment room should be such that the computer, tape cassette storage shelves, and cassette playback equipment are in optimun close proximity for the operator efficiency.

The purpose of the design is to develop a true random access media retrieval system which is individual in character and provides a broad selection capability. It is expected that the problems and frustrations experienced by users described above will be eliminated. Advantages include the ability: to select any lesson in the tape col. lection at any time; to start the lesson from the beginning; and to have full independent control of the lesson. This process can be from any touch-tone source (external telephone, on-campus student station, or cr-campus telephone).

The technical features of computer control and switching can be extended to video cassette equipment. Although video is not specifically a part of this project, it is expected that, contingent upon the success of this project, video development will be considered at a later time. 
2.3 Other commercially available systems.

The Ampex PYRAMID $(5,6,7,8)$ random access system is the only commercially available system which offers individual control to cach terminal and high speed random access to information (approximately 30 seconds per one-half hour lesson tape time). The PYRAMID system employes very high speed duplication (120 inches per second) and computer control. It has two drawbacks: 1) the maximum rumber of lessons available is a function of the number of 32 track master program tape transports and 2) its very high cost.

Chester Electronic Laboratories, a division of G.T.E. Information Systems, was the original dial access audio information retrieval system manufacturer in the United States: the first dial access laboratory was developed at the University of Michigan in 1961 by Chester (10). The initial success of this experimental installation has led to proliferation of both audio and visual systems. It is reported (11) that in 1968, 121 such systems had been installed nationwide, most of which were Chester systems. In 1972 Chester Electronic Laboratories discontinued operations because of continuing losses and all other major American manufacturers of dial access systems were out of busiress for the same reason.

The Millhouse (1) crosspoint dial access system being tested in German universities is very similar to the Ampex Pyramid system. The main objection here is the limitation on the total number tapes available to the user.

Another educational application is that of either individual or class contact with a distant instructor via telephone. Systems of this type include: the San Francisco Educational Switchboard (12); Rome, Italy's consultancy-by-telephone (13); Finger Lakes' Telephone Class (14), to mention a few. The main distinguishing characteristic of this method is the element of live classroom situations. The design described in this paper is not meant to replace this application, nor is it meant to supplant any of the other types of learning media systems. Each serves a distinct furction usually unique to itself.

\section{System Operation and Control}

\subsection{Computer control.}

Figure 3.1 is a block diagram of the system. The system is a "star" type configuration since all operations and controls are managed by the computer (center of star). Tape decks, student stations, and telephone couplers may be envisaged as points of the star.

The computer system is essentially operating in a time sharing mode. That is, all control functions are performed serially because the computer executes only one instruction at a time. The organi- 


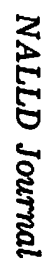

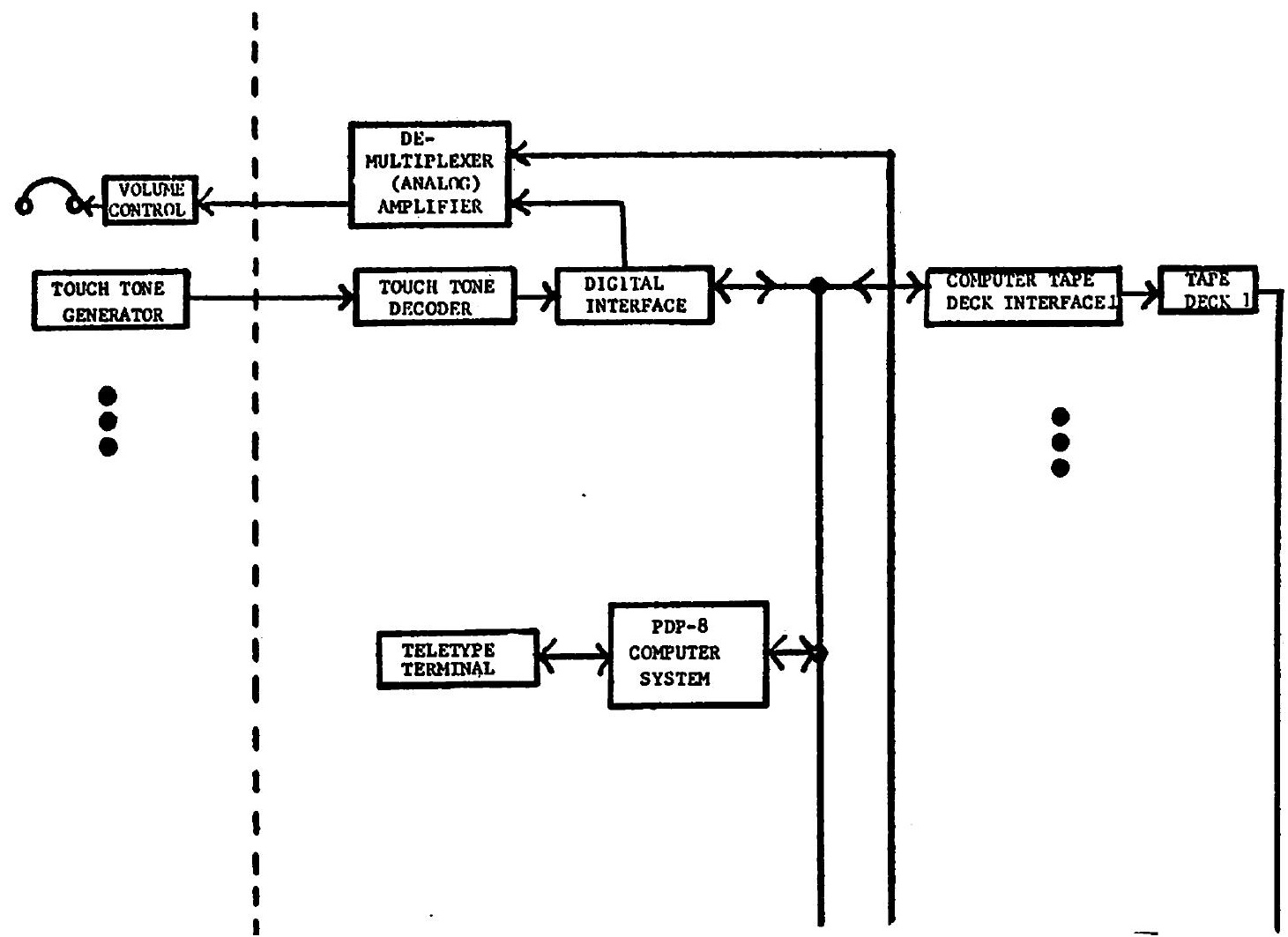




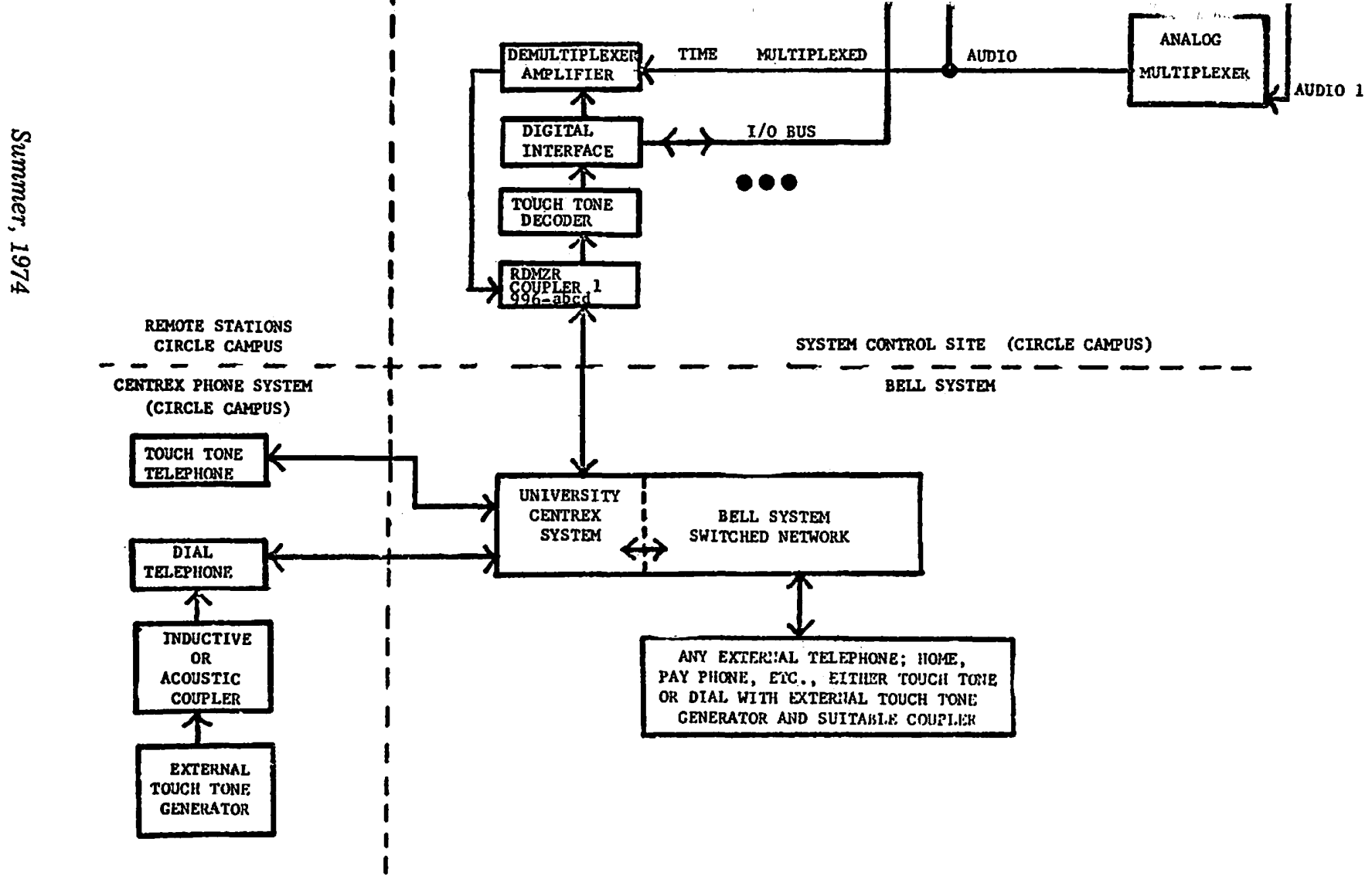




\section{Automated Retrieval}

zation of the management and control program is such that all terminal requests (users or operator inputing data) are processed on a priority interrupt bases. That is, while the computer is performing some relately low priority task, such as bookkeeping, a user inroutine detects the character " $O$ " and prints the following message to process the user's data.

The mechanism for transmission of data from the user to the computer is basically simple. When the user depresses a button on the touch-tone keyset, the generator emits two tones which are decoded in the touch-tone decorder and converted to a binary coded direct $(B C D)$ number. The presence of this number in the digital interface (Figure 3.1) sets the interrupt mechanism described above. The data management program determines the disposition of the data. If the data is another type of control command (call operator, select new program, etc.) the appropriate action is taken.

It should be noted that the features available to the user are identical whether the place of acces is an on-campus student station, on-campus telephone, or the Bell System switched network.

3.2 Keyboard Commands

The purpose of the keyboard commands is to give the system operator easy access to status information about all or any part of the system. All the commands are displayed on the teletype printer. The symbol $\downarrow$ following a command indicates striking the "return" key on the keyboard. The following is a description of the keyboard commands.

1. Zero, $Z \downarrow$. This command is used to set all entries of both station and deck status tables equal to zero.

2. Modify deck ready status, $\mathrm{Mx} \$ \mathrm{z} \downarrow$ or $\mathrm{Mx}, \mathrm{y} \$ \mathrm{z} \downarrow$.

The symbol $x$ represents the one or two digit number of the first or possibly only deck whose status entry is to be modified. The symbol y represents the one or two digit number of the last deck whose status entry is to be modified. The symbol $\mathrm{z}$ represents either the letter $\mathbf{R}$ or $\mathrm{N}$ corresponding to the actual status of the tape deck.

Example M3\$R $\downarrow$ sets the ready status entry of deck 3 to $R$ or ready M10, $30 \$ N ~ \&$ sets the ready status entries of decks 10 through 30 to $\mathrm{N}$ or not ready.

3. Display tape deck status and contents, Dx $\downarrow$ or Dx,y $\downarrow$. The symbols $\mathrm{x}$ and $\mathrm{y}$ have the same meaning as above. Entering the $\mathrm{Dx} \downarrow$ command causes the following line to be printed on the teletype printer:

DECK $\times 2$ ASSIGNED TO $k$ PROG abcd

The symbol $\mathrm{z}$ represents the status ( $\mathrm{R}$ or $\mathrm{N}$ ), $\mathrm{k}$ represents the number of the station using this deck and abcd represents the call number of the tape presently loaded. 


\section{Automated Retrieval}

Example D-1, $2 \downarrow$ causes the following lines to be printed on the teletype:

DECK 1 R ASSIGNED TO 31 PROG 7732

DECK $2 \mathrm{~N}$ ASSIGNED TO 00 PROG 7134

4. Change tape call number, Dx\$abcd $\downarrow$. The symbols $x$ and abcd have the same meaning as above. This command allows the operator to change the tape loaded on the deck and modify the second word of the deck status entry.

5. Display input station status, $S x \downarrow$ or $S x, y \downarrow$. This command is identical to the $\mathrm{D}$ command in 3 above except the following line is printed on the teletype: STAT $\times$ ASSIGNED TO $\mathrm{k}$ PROG abed

3.3 Tape deck assignment

When the computer is not processing interrupts or interacting with the operator it is constantly checking the student stations for completed lesson tape requests. When a completed request is found the process for deck assignment commences. The computer first attempts to locate a deck which is ready, not assigned to any other station, and has the desired tape already loaded. This is accomplished by the first pass checking of the deck status table. If no deck is available with the desired tape preloaded a second pass check is made to find a ready deck with no tape loaded. If the second pass is successful the following message is printed on the teletype:

LOAD PROG abcd ON DECK $x$

Where abcd is the call number and $\mathrm{x}$ is the deck number. If the second pass is unsuccessful, a third pass is initiated seeking a ready deck not assigned to any station but with some other call number tape preloaded. In this case the same message as in pass 2 is printed. After completing the assignment, the entries in both tables are updated, and the program resumes checking the status tables. Should pass 3 be unsuccessful, meaning no decks in working order are available, the following message is printed on the teletype:

NO DECK AVAILABLE FOR STAT X

At this juncture, the operator must communicate with the station involved and take whatever measures are necessary to correct the deficiency.

The operator call feature is activated when the user depresses the "O" or operator key on the touch-tone pad. The interrupt service puting data will immediately interrupt the computer from that task on the teletype:

STATION X CALLING

Also, the teletype bell is rung twice.

The select new lesson feature is activated when the user depresses the "*" button. When the interrupt service routine detects this character, the station and deck assigned entries are set equal to zero in the second word of the station status entry. 


\section{Automated Retrieval}

Finally, every time a deck control command is issued by the computer to a tape deck, a check is made to determine if the deck responds to the command. If the check reveals that the deck did not respond, the following message is printed on the teletype:

\section{DECK $x$ CAN'T CONTROL TD y}

The purpose of this message is to automatically inform the operator of a probable failure before the user experiences frustration in attempting to control his lesson. One possible cause of difficulty is broken tape which the operator may not notice.

Although not included in the present design, an additional necessary feature for a practical system is the individual system of records for each tape in the library. Each tape in the system library will have a two word record on computer disk file consisting of the following information: 1) number of original copies of the tape, 2) the number of user requests per some unit of time (probably weekly),

3) the maximum number of copies used simultaneously, and 4) the current number of copies (which may be greater than the original number of copies.)

\section{The Minicomputer}

\subsection{General Discussion}

The practicality of the system being described in this paper is attributable to the minicomputer. The switching, control and logic operations necessary for this system are relatively complex. The inadequacies associated with the Chester (and other) audio information retrieval systems are, to a great extent, due to the lack of flexible switching and logic capability. Essentially, the switching mechanism employed in these systems are the step-by-step relay type. They are slow and single function, that is, call routing mechanisms with no optimizing capabilities whatsoever.

The minicomputer is a flexible, programmable process control machine which offers the advantages of speed, cost effectiveness, and a unified but input-output capability. The Digital Equipment Corp. PDP.8 (Program Data Processor) is generally considered the earliest minicomputer: the first version of the PDP-8 was released in 1965. In 1968, DEC introduced the integrated circuit version of the original computer, the PDP-8/I. The evolution of the PDP-8 series is shown in table 4.1. (15). 
Year of

first

$\frac{\text { delivery }}{1965} \quad \frac{\text { Model }}{\text { PDP-8 }}$

1966

1968

1968

1971

1971

1972

\begin{tabular}{c}
$\begin{array}{c}\text { Price } \\
\text { (in thousands } \\
\text { of dollars) }\end{array}$ \\
\hline 18 \\
10 \\
16 \\
8 \\
5 \\
3.7 \\
4
\end{tabular}

\begin{tabular}{|c|c|}
\hline $\begin{array}{c}\text { Storage } \\
\text { cycle } \\
\text { (micro sec) }\end{array}$ & $\begin{array}{c}\text { Add } \\
\text { time } \\
\text { (micro sec) }\end{array}$ \\
\hline 1.5 & 3.0 \\
\hline 8 & 33.0 \\
\hline 1.5 & 3.0 \\
\hline 1.6 & 3.2 \\
\hline 1.2 & 2.6 \\
\hline 1.2 & 2.6 \\
\hline 1.2 & 2.6 \\
\hline
\end{tabular}

Table 4.1 Minicomputer evolution

The decreasing price trend is the most notable feature in table 4.1. The 8/S model was introduced at less than $\$ 10,000$ in 1966 but at a cost of substantially degraded performance - slow memory and serial arithmetic. When the $8 / \mathrm{I}$ introduced integrated circuits to the family, it offered little improvement in performance over the original 8 but there was a decrease in price and reduction in physical size. A suitable main frame processor such as the model $8 / \mathrm{E}$ for use in this design can be purchased for about $\$ 5,000$. The improvements in functions and features over the Chester system are obvious. It should be noted that the original cost of the Chester relay switching system presently in use at U.I.C.C. was about $\$ 30,000$. The minicomputer performs all switching operations in a far more efficient, effective, and elegant manner for about $1 / 6$ the cost. In addition, the minicomputer performs system optimization, record keeping, and operator communications - all impossible with the present system. The minicomputer employed in the development and testing of the design model is the PDP-8/I owned by the Information Engineering Department of the University of Illinois at Chicago Circle College of Engineering and housed in the small computer laboratory. The features of the system include two fields of core memory, 4096 words each; the extended arithmetic unit; one 32,767 word DF-32 disk, one digital cassette tape unit; the model 33 teletype input-output terminal, and a model 666 Tektronics storage display scope.

The management and control program was developed using the $\mathrm{PS} / 8$ operating system. The PS/8 is a highly flexible operating system which provides access to individual files on external devices through software "device handlers." PS/8 used in conjunction with certain utility routines such as PIP (Periphal Interchange Program), EDIT (system editor), ABSLDR (the absolute binary loader), and PAI-8 (the assembler), allows development of a complete assembly language program. 


\section{Automated Retrieval}

\section{Conclusions}

The realization of the functional criteria identified in the preliminary stages of the design necessitated an extensive and flexible logic and control capability. Futhermore, the logic decisions and controls must have the capacity of occurring in rapid succession. These requirements are obviously met by a high speed, programmable digital computer. Emphasis is placed on the word programmable for several reasons. The data management and control program, in its present form, is a skeletal structure. Many additional features should be added to enhance the general value and efficiency of the system. For example, the tape record keeping program is an extremely imnortant feature yet to be developed. The tape deck assignment and -ptimization routines should be expanded to include a lesson priority check when it is necessary to remove a pre-loaded tape from the system, (i.e.) on the basis of certain tape usage data, the computer should decide which, of a given set of currently loaded, not-in-use tapes, are least likely to be selected at any time. Additional operator and user interaction features are necessary. All these modifications are impossible unless the computer is programmable. The alternative to a programmable computer is a hard wired logic and switching system or a fixed program processor, both of which are inflexible, and ineffective in a growing and changing system.

From the outset, the system, as designed, can be modified continuously without interruption in service. The present version of the system is fully workable but has a minimum set of functions. Future software (program) development can be accomplished on another computer and the de-bugged version loaded in a matter of minutes.

Although the pilot system is a skeleton with limited application as it stands, it serves as a foundation for a total effect. From a research standpoint, the project represents the completion of a goal. The research commenced by studying the current state of audio information systems and identifying their shortcomings. On the basis of the information acquired in the study the new system was designed and a model constructed. Evidence of the completed goal manifests itself in the form of the working model. No final conclusion can be drawn from the concept formulated and studied in this paper. Such a conclusion could be drawn only after study of the system under actual operating conditions. Preliminary conclusions concerning time estimates for functional processing and certain other features were presented in the text. It is not unreasonable to conclude, however, that the model constructed does in fact perform as described and that it does serve as a basis for further development. 


\section{REFERENCES}

1. Hill, Brian. "Language Teaching Hardware," The Times Educational Supplement, 2974 (May 19, 1972), 58.

2. Price, Hilary. "On Language Laboratories," The Times Educational Supplement, 2962 (February 25, 1972), 54.

3. Commission on Instructional Technology. "To Improve Learning a report to the President and the Congress of the United States," Committee on Education and Labor - House of Repre.. sentatives, Washington, D.C. (March, 1970).

4. Morrison, Joseph F. "The UICC Home Telephone Access System," Illinois Journal of Education, (March-April, 1972), p. 57.

5. Johnson, Ted. "An Information Retrieval System of the Future," North Central Association Quarterly, 41 (Spring, 1967), 309315.

6. Johnson, Ted. "Dial, Remote and Random," ALA Bulletin, 62 (October, 1968), 1085-1088.

7. Johnson, Ted. "Learning How to Apply the First True RandomAccess Learning System," Audiovisual Instruction, 16 (October, 1971), 78-81.

8. Johnson, Ted. "New Technology and Old Intentions," Illinois Education, 58 (April, 1970), 322-324.

9. "CCTV Tunes in Finer Instruction at WVS," College and University Business, 53 (October, 1972), 48.

10. Crossman, David M. "The Current State of the Remote-Access Audio Video Information System," Audiovisual Instruction, 15 (September, 1970), 20-23.

11. Ofiesh, Gabriel D. "'Dial Access Information Retrieval Systems," Guidelines Handbook for Educators, Catholic University of America (1968).

12. Goldman, Jacques. "San Francisco's Education Switchboard," The Times Educational Supplement, 2958 (January 28, 1972), 13.

14. Rookey, Ernest J., Gill, Lester W., and F. Jean. "An Educational Telephone Network," Educational Technology, 11 (December, 1971), 37-39.

15. Riley, Wallace B. "Minicomputers Go Into Action in a Myriad of Application," Electronics, vol. 46, no. 7, (March 29, 1973), 72-81. 